Afonso Ceiso Pinto Nazário 1

Luiz Alberto Sobral Vieira JúNiOR ${ }^{2}$

JANINE MARTINS MACHADO

CLÁUDIO KEMP

Relato de caso

Palavras-chaves

Neoplasias mamárias/induzido quimicamente

Fibroadenoma/diagnóstico

Fibroadenoma/induzido quimicamente

Ciclosporina/efeitos adversos Transplante rena Imunossupressores/efeitos adversos Tolerância imunológica

Doenças da mama

Diagnóstico por imagem

Keywords

Breast neoplasms/chemically induced

Fibroadenoma/diagnosis Fibroadenoma/chemically induced

Cyclosporine/adverse effects

Kidney transplantation Immunosuppressive agents/adverse effects

Immune tolerance Breast diseases Diagnostic imaging

\section{Múltiplos fibroadenomas bilaterais após transplante renal e imunossupressão com ciclosporina A}

\author{
Multiple bilateral fibroadenomas after kidney transplantation and \\ immunossuppression with cyclosporine A
}

\section{Resumo}

O fibroadenoma é a neoplasia benigna mais freqüente da mama feminina e é considerado tumor misto, constituído por quantidades variáveis de tecido conjuntivo e epitelial. A ciclosporina parece ter implicações no desenvolvimento de fibroadenomas mamários em pacientes transplantadas renais em idade reprodutiva. Descrevemos o caso no qual a paciente, em uso terapêutico de ciclosporina A, após transplante renal, apresentou vários nódulos mamários bilaterais na evolução. $O$ exame físico e os achados de imagem sugeriram fibroadenoma, diagnóstico que foi confirmado após biópsias.

\section{Abstract}

Fibroadenoma is the most frequent benign neoplasia in the female breast and it is considered a mixed tumor, constituted by variable amounts of connective and epithelial tissue. Cyclosporine A seems to be related with the development of mamary fibroadenomas in patients who underwent kidney transplantation in reproductive age. We reported the case in which the patient, in therapeutic use of cyclosporine A, after kidney transplantation, presented several bilateral lumps. The imaging and palpable findings suggested fibroadenoma, confirmed after biopsy.
Correspondêncio: Luiz Alberto Sobral Vieira Júnior Rua Constante Sodré, 1179/802, Praia do Canto (EP 29055-420 - Vitória/ES Fone: (27) 3227-7072/9982-4597 E-mail:luizsobral@terra.com.br

Recebido $25 / 07 / 2006$

Aceito com modificacões $23 / 04 / 2007$
Disciplina de Mastologia do Departamento de Ginecologia da Escola Paulista de Medicina da Universidade Federal de São Paulo - UNIFESP - São Paulo (SP), Brasil.

Chefe do Departamento de Ginecologia da Escola Paulista de Medicina da Universidade Federal de São Paulo - UNIFESP São Paulo (SP), Brasil.

Pós-graduando da Disciplina de Mastologia do Departamento de Ginecologia da Escola Paulista de Medicina da Universidade Federal de São Paulo - UNIFESP - São Paulo (SP), Brasil; Coordenador do programa de Residência Médica de Mastologia da Universidade Federal do Espírito Santo - UFES - Espírito Santo (ES), Brasil.

3 Pós-graduanda da Disciplina de Mastologia do Departamento Ginecologia da Escola Paulista de Medicina da Universidade Federal de São Paulo - UNIFESP - São Paulo (SP), Brasil.

${ }^{4}$ Chefe da Disciplina de Mastologia do Departamento de Ginecologia da Escola Paulista de Medicina da Universidade Federal de São Paulo - UNIFESP - São Paulo (SP), Brasil. 


\section{Introdução}

O fibroadenoma é o tumor benigno mais comum da mama feminina, com pico de incidência entre a segunda e a terceira décadas de vida, que é também o período de mais intensa esteroidogênese no menacme $e^{1,2}$. Deriva do epitélio e do estroma da unidade terminal ducto-lobular, sendo classificado como neoplasia benigna mista $^{3}$. Apresenta-se como nódulo bem delimitado e móvel em relação aos tecidos circunvizinhos, geralmente único, podendo, no entanto, ser múltiplo em 13,4 a $16 \%$, Seu diagnóstico pode ser feito clinicamente, por exame físico, e por métodos de imagem, como a ultrasonografia e a mamografia. O diagnóstico definitivo é histopatológico. $\mathrm{Na}$ maioria dos casos, o fibroadenoma é solitário e palpável pela paciente. A maioria dos fibroadenomas tem menos que $3 \mathrm{~cm}$ de diâmetro e apenas $10 \%$ são maiores que $4 \mathrm{~cm}^{5,6}$.

As formas múltiplas correspondem a $20 \%$ dos casos. É incomum, entretanto, se encontrarem mais que cinco fibroadenomas na mama ${ }^{7}$, embora já tenham sido descritas síndromes familiares ou hormonais que cursam desta maneira. Fibroadenomas múltiplos gigantes são ainda mais raros, eventualidade encontrada em adolescentes negras 5 e que recentemente tem sido correlacionada com imunossupressão com uso de ciclosporina $\mathrm{A}^{6-8}$. Neste grupo de pacientes, com freqüência recorrem após excisão ou há o surgimento de nova lesão. Em alguns casos, os fibroadenomas múltiplos gigantes produzem aumento global da mama com deformidade bilateral, às vezes sendo necessária mastectomia ${ }^{6}$.

A ciclosporina A apresenta vários efeitos adversos conhecidos, tais como piora da função renal, hipertensão, predisposição a infecções, hipertricose, tremor fino, transtorno da função hepática e hiperplasia gengival ${ }^{9,10}$. Apesar de aumentar a incidência de vários tumores na mama, em especial dos tecidos linfo-reticulares, a ciclosporina A diminui o risco relativo para neoplasia maligna, porém incrementa a incidência de tumores benignos ${ }^{11,12}$. Seu efeito promotor em tumores benignos da mama do tipo fibroadenoma tem prevalência ainda não bem determinada, já que as referências na literatura a este respeito são escassas ${ }^{7}$. Alguns autores ${ }^{6,8}$ propõem existir dois mecanismos: relação com uma ação direta sobre os fibroblastos, já que alguns fibroblastos possuem receptores para ciclosporina $A$, e ação sobre o eixo hipotálamo-hipofisário, com diminuição do hormônio luteinizante (LH) e de testosterona, podendo ocorrer ginecomastia em homens. Neste trabalho, nosso objetivo foi descrever um caso no qual a paciente, em uso terapêutico de ciclosporina $A$ após transplante renal, apresentou vários nódulos mamários bilaterais na evolução, e realizar levantamento da literatura sobre esta associação, na qual encontramos apenas uma referência brasileira.

\section{Descrição do caso}

Paciente do sexo feminino, 47 anos, negra, apresentou menarca aos 13 anos, era primípara e seu único parto havia ocorrido aos 16 anos. Apresentava ainda ciclos menstruais regulares.

Foi atendida pela primeira vez no ambulatório da Disciplina de Mastologia da Universidade Federal de São Paulo - UNIFESP - em agosto de 2002, com queixa de há sete meses ter percebido vários nódulos em ambas as mamas. Havia sido submetida a transplante renal em agosto de 1998 e, desde então, recebia terapia imunossupressora com prednisona e ciclosporina A.

Ao exame físico, paciente em bom estado geral, mucosas coradas, apresentava mamas volumosas com abaulamentos, sem alterações de pele. Vários tumores foram palpados, de consistência fibroelástica, móveis e regulares, sugerindo benignidade. Não havia comprometimento axilar.

$\mathrm{Na}$ mamografia apresentava mamas volumosas, padrão de alta densidade, e foram identificados vários nódulos de bordos regulares bilaterais, sendo 12 à esquerda e dez à direita (Figura 1). À ultra-sonografia, estes nódulos eram hipoecogênicos, porém, com ecogenicidade interna maior que a usualmente encontrada em fibroadenoma, de limites precisos, o maior deles localizado no quadrante súpero-lateral da mama esquerda, justa-areolar e medindo 4,2 cm (Figura 2). Foi realizada punção aspirativa com agulha fina, mostrando tratar-se de nódulos sólidos.

A análise citológica foi negativa para malignidade e era representada por esfregaço de fundo hemorrágico com poucas células epiteliais típicas isoladas e em fileiras.

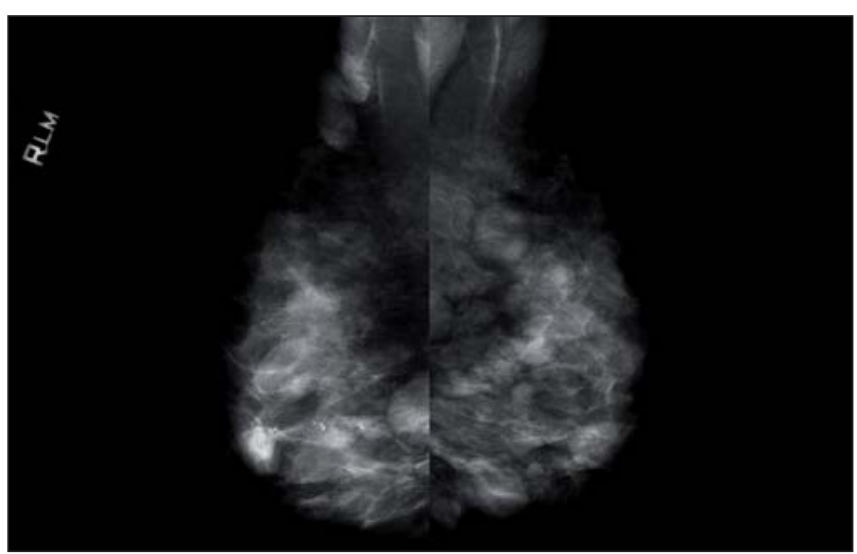

Figura 1 - Mamografia: mamas volumosas com múltiplos nódulos de bordos regulares bilateralmente. 
Em fevereiro de 2003, foi submetida à exérese do maior nódulo da mama direita e de dois na mama esquerda, nos quadrantes súpero-lateral e ínfero-medial, que mediam, respectivamente, 5,3 e $3 \mathrm{~cm}$. O exame anatomopatológico mostrou, na macroscopia, nódulos brancacentos, borrachosos, de contornos bocelados e bordos bem definidos e, na microscopia, eram representados por estroma constituído por trama de células fibroblásticas com núcleos pequenos e alongados, que envolvia uma proliferação atípica de ductos e ácinos, com nítido predomínio do tecido fibroso, com o componente epitelial estirado, comprimido pelo estroma em arranjos curvilíneos, confirmando a hipótese de fibroadenoma, variedade intracanalicular, que em nada difere dos fibroadenomas comuns (Figura 3). Atualmente a paciente continua em observação no ambulatório de mastologia, apresentando nódulos bilaterais sem crescimento aparente, mantendo-se em uso de ciclosporina $\mathrm{A}$.

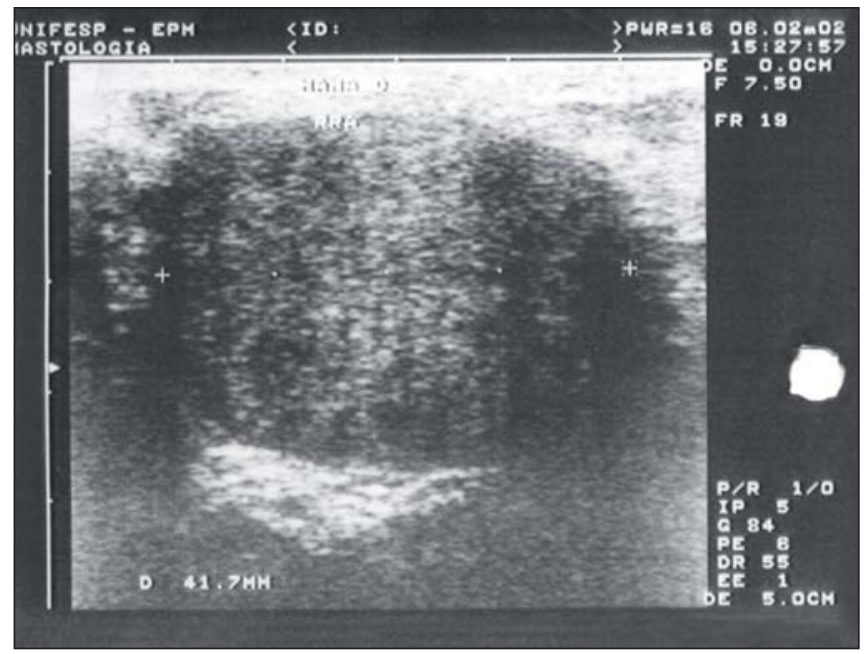

Figura 2 - Avaliação ultra-sonográfica: nódulo hipoecóico com 4,2cm de bordos regulares, com ecogenicidade interna um pouco maior que a usualmente encontrada no fibroadenoma.

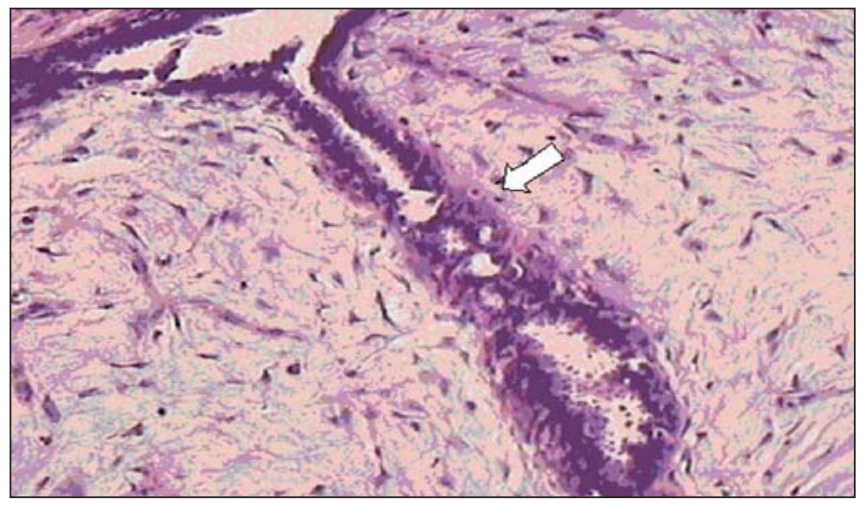

Figura 3 - Avaliação histopatológica: fibroadenoma HE 40X. Na seta, observar componente epitelial estirado, comprimido pelo estroma em arranjos curvilíneos, confirmando a hipótese de fibroadenoma, variedade intracanalicular, que em nada difere dos fibroadenomas comuns.

\section{Discussão}

A associação entre a ciclosporina A e neoplasias malignas de outros sítios não mamários já é bem conhecida ${ }^{10-12}$, tendo sido demonstrado em usuárias de ciclosporina $\mathrm{A}$ aumento da incidência dos dez principais tipos de cânceres, em particular de pele e do sistema linfo-reticular. Em contrapartida, observou-se menor incidência de câncer de mama, sendo particularmente baixa no primeiro ano pós-transplante.

Em série de 39 mulheres transplantadas renais ${ }^{8}$ foram encontrados fibroadenomas em 13 de 29 mulheres que usaram ciclosporina $\mathrm{A}$. As lesões foram múltiplas em dez, e, em cinco casos, foram bilaterais. Por outro lado, não observaram achados anormais em dez transplantadas renais tratadas com esteróides e azatioprina, ressaltando que a alta prevalência de fibroadenomas poderia ser resultante da ciclosporina A.

$\mathrm{Na}$ mama, parece existir constante equilíbrio entre os fatores estimuladores (estrogênio, progesterona, EGF, IGF 1 e FGFs) que promovem a proliferação celular e a família TGF- $\beta$, que junto com o fator de necrose tumoral (TNF) estimulam a apoptose ${ }^{13}$. O fibroadenoma provavelmente resulta do desequilíbrio entre a proliferação e a apoptose, favorecendo o crescimento de tumor benigno, que se origina concomitante ao desenvolvimento mamário na puberdade. Contudo, devido ao lento crescimento, estes são detectados entre os 20 e 30 anos $^{5}$. Assim, sua freqüência, tamanho e crescimento podem, em tese, ser influenciados por diversos fatores e, nos últimos anos, têm sido relacionados ao uso de ciclosporina $A^{6-8}$.

A ciclosporina $\mathrm{A}$ inibe os linfócitos ${ }^{14}$ por bloquear a produção de interleucina 2 , alterando a regulação do seu gene, e poderia favorecer o crescimento dos fibroadenomas, talvez por alterar a produção de fatores de crescimento, causando o desequilíbrio entre a proliferação e apoptose, com uma ação direta sobre os fibroblastos, já que estes podem possuir receptores para ciclosporina $A^{6-8,15-18}$. Assim, a ciclosporina A parece interferir na secreção de citocinas ligadas a proliferação e apoptose do epitélio mamário, interferindo no crescimento, desenvolvimento e aparecimento de fibroadenomas múltiplos e gigantes em usuárias desta droga $a^{6-8,15}$, e, em casos graves, a mastectomia subcutânea pode ser necessária ${ }^{6,15}$.

Pode ocorrer ainda ação sobre o eixo hipotálamohipofisário, com diminuição do LH e de testosterona, já demonstrada em ratos, com alteração da conversão periférica de andrógenos em estrógenos, com maior estímulo proliferativo sobre a mama ${ }^{6,8}$.

Em estudo retrospectivo envolvendo mulheres transplantadas renais, usando terapia imunossupressora com 
ciclosporina A e prednisona, observou-se que fibroadenomas eram múltiplos e bilaterais, com tamanho médio de $4,2 \mathrm{~cm}$, circunscritos, com alta densidade à mamografia e, na ultra-sonografia, apresentavam ecogenicidade aumentada, com razão entre diâmetro longitudinal e ântero-posterior menor que o grupo controle ${ }^{19}$.

Fato que confirma a relação da ciclosporina A com o desenvolvimento de fibroadenomas é o relato de casos no qual a troca do imunossupressor leva à regressão dos nódulos ${ }^{17,18,20-22}$.

Importante estarmos atento à necessidade de diagnóstico diferencial com linfoma, tumor raro na mama, mas que tem sua incidência aumentada em usuárias de ciclosporina e também com tumor filóides, ambos geralmente únicos ${ }^{11,12,16}$.

Não existe, porém, nenhum estudo prospectivo que tenha avaliado a prevalência de fibroadenomas em imunossuprimidas usuárias de ciclosporina A. O conhecimento da prevalência de fibroadenomas em pacientes renais crônicas transplantadas e imunossuprimidas em uso de ciclosporina A bem como o uso dessa droga induz ao desenvolvimento de fibroadenomas pode trazer informações úteis ao melhor conhecimento do mecanismo de controle da proliferação do epitélio mamário, assim como dos mecanismos parácrinos e autócrinos de interação entre estroma e epitélio na glândula mamária feminina, buscando melhor juízo clínico para o manejo das doenças mamárias mais comuns.

Acreditamos que a paciente aqui descrita represente um caso de fibroadenoma induzido pela ciclosporina, semelhante aos previamente descritos por outros autores. No entanto, o mecanismo preciso da ação da ciclosporina A precisa ser mais bem elucidado. Destaca-se a importância de um efeito medicamentoso ainda subestimado, em tempos em que há crescimento em larga escala de transplantes e terapêutica imunossupressora para várias doenças auto-imunes e inflamatórias.

\section{Referências}

1. Rosen PP, Menendez-Botet CJ, Nisselbaum JS, Urban JA, Mike V, Fracchia $A$, et al. Pathological review of breast lesions analyzed for estrogen receptor protein. Cancer Res. 1975;35/11 Pt 1):3187-94.

2. Allegra JC, Lippman ME, Green L, Barlock A, Simon R, Thompson $E B$, et al. Estrogen receptor values in patients with benign disease. Cancer. 1979;44(1):228-31

3. Robbins SL, Cotran RS, Kumar V. The breast: pathologic basics of diseases. 5th ed. Philadelphia: WB Saunders; 1996. p. 1089-110.

4. Haagensen CD. Diseases of the breast. 3rded. Philadelphia: WB Saunders; 1986. p. 274.

5. Dent DM, Cant PJ. Fibroadenoma. World J Surg. 1989;13(6):706-10.

6. Cyrlak D, Pahl M, Carpenter SE. Breast imaging case of the day. Multiple giant fibroadenomas associated with cyclosporin A therapy. Radiographics. 1999;19(2):549-51.

7. Weinstein SP, Orel SG, Collazzo L, Conant EF, Lawton TJ, Czerniecki B. Cyclosporin A-induced fibroadenomas of the breast: report of five cases. Radiology. $2001 ; 220(2): 465-8$.

8. Baildam AD, Higgins RM, Hurley E, Furlong A, Walls J, Venning $M C$, et al. Cyclosporin $A$ and multiple fibroadenomas of the breast. Br J Surg. 1996;83(2):1755-7.

9. Bennett WM, Norman DJ. Action and toxicity of cyclosporine. Ann Rev Med. 1986;37:215-24.

10. Datta A, David R, Glennie S, Scott D, Cernuda-Morollon E, Lechler $\mathrm{RI}$, et al. Differential effects of immunosuppressive drugs on T-cell motility. Am J Transplant. 2006;6(12):2871-83.

11. Stewart T, Tsai SC, Grayson H, Henderson R, Opelz G. Incidence of de-novo breast cancer in women chronically immunosuppressed after organ transplantation. Lancet. 1995;346(8978):796-8.

12. Agraharkar ML, Cinclair RD, Kuo YF, Daller JA, Shahinian VB. Risk of malignancy with long-term immunosuppression in renal transplant recipients. Kidney Int. 2004;66(1):383-9.
13. Swiatecka J, Laudanski P, Dzieciol J. Fine needle aspiration cytology of benign brest disease. Markers of apoptosis and proliferation. Neoplasma. 2004;51(1):49-55.

14. Kasaian MT, Biron CA. Cyclosporin A inhibition of interleukin 2 gene expression, but not natural killer cell proliferation, after interferon induction in vivo. J Exp Med. 1990;171(3): 745-62.

15. Kollias J, Gill PG, Leong AS, Clarkson AR. Gynaecomastia presenting as fibroadenomatoid tumours of the breast in a renal transplant recipient associated with cyclosporin treatment. Aust N Z J Surg. 1998;68(9):679-81.

16. Muttarak M, Peh WC, Chaiwun B, Lumlertgul D. Multiple bilateral giant fibroadenomas associated with cyclosporine $A$ therapy in a renal transplant recipient. Australas Radiol. 2001;45(4):517-9.

17. Caetano Stefenon C, de Oliveira Lima R, Gualandi Murad AL. Cyclosporine and the development of multiple mammary nodules. Breast J. 2002;8(3):177-9.

18. Balal M, Seyrek N, Karayaylali I, Paydas S. Report of a renal transplanted patient with fibroadenoma occurring in a short time. Transplant Proc. 2003;35(4): 1408-9.

19. Son EJ, Oh KK, Kim EK, Cho N, Lee JD, Kim SH, et al. Characteristic imaging features of breast fibroadenomas in women given cyclosporin A after renal transplantation. J Clin Ultrasound. 2004;32(2):69-77.

20. Alkhunaizi $A M$, Ismail $A$, Yousif $B M$. Breast fibroadenomas in renal transplant recipients. Transplant Proc. 2004;36(6): 1839-40.

21. Binokay F, Balal M, Demir E, Paydas S, Soyupak S, Sertdemir $Y$, et al. Risk of developing fibroadenoma with the use of cyclosporine $\mathrm{A}$ in renal transplant recipients. Ren Fail. $2005 ; 27(6): 721-5$.

22. Seo YL, Choi CS, Yoon DY, Yun EJ, Lee YJ, Park SJ, et al. Benign breast diseases associated with cyclosporine therapy in renal transplant recipients. Transplant Proc. 2005;37(10): 4315-9. 